\title{
Introduction: How Prices Rose and Lives Changed
}

\author{
Patta Scott-Villiers and Alexandra Wanjiku Kelbert
}

\begin{abstract}
Between 2007 and 2012 global food price volatility affected millions of people on low and precarious incomes. Research partners from ten developing countries accompanied households in rural and urban sites, from just after the first price spike in 2008, through a second spike in 2011 and into a period of relative price stability until 2014. In this IDS Bulletin we show how a multitude of micro-reactions to rising and unpredictable prices has laid the foundations for transformed societies. As food has been increasingly commodified, as people on low incomes have struggled to pay for life's necessities, as they have responded by changing their ways of making a living, residences, diets, family relationships and ways of caring for one another, we map out how food price volatility has played a part in global social change.
\end{abstract}

\section{A time of food price volatility}

What changes are wrought in times of economic uncertainty among people on low and precarious incomes and how do they come about? In 2007 prices for staple grains and other key foodstuffs on global markets spiked sharply, and then continued to rise, reaching a peak in mid-2008. Throughout 2009 and 2010 they fell and in 2011 they spiked again, reaching levels higher than they had ever been. ${ }^{1}$ Global food prices began to fall again in 2012 and continued to do so into 2015. Few national food markets were insulated from the price volatility, even in countries self-sufficient in staple foods, but the pattern and degree of shock varied from one country to another, and from one market to another, as might be expected. Despite peaks and troughs, over the period the general trajectory of prices of most major food commodities in most national and local markets has been upwards; prices are now higher in real terms than they were in the previous period of stability, 1975-2005.

Welcome to a time of food price volatility, the topic of this issue of the IDS Bulletin. Written by the members of the collective of researchers from ten countries, each of whom carried out a longitudinal study into the impacts and effects of food price volatility over three years (or in some cases longer), this IDS Bulletin aims to elucidate two critical areas of scholarship, one empirical and the other methodological. First, it gives insights into how people on low incomes across the developing world reacted to food price volatility and how that led to transformations at multiple levels. It shows how people whose lives are already precarious are the ones who have absorbed and continue to bear the often high costs of these transformations. Second, it demonstrates the usefulness of a social research method that works longitudinally to understand the mechanisms by which social change comes about in relation to a macro-event like the global food crisis.

Whether the time of volatility is now over is a moot point, addressed by Richard King in his article in this IDS Bulletin. Some claim that volatility is inherent to an integrated globalised system.

Others that since the global food crisis of 2007/08 governments have individually and in blocs adjusted policies in order to prevent the return of volatility. No one is ruling it out, however. Presenting the OECD-FAO annual Agricultural Outlook report in Paris in July 2015, OECD Secretary General Angel Gurría said: 'The outlook for global agriculture is calmer than it has been in recent years, but there is no room for complacency, as we cannot rule out the risk of new price spikes in the coming years'. ${ }^{2}$ The 2007/08 price spike began with weatherrelated production shocks coupled with low stockto-use ratios. In August 2015, the UK Global Food Security Programme reported that 'an event that we would have called 1-in-100 years over the period 1951-2010 may become as frequent as a 1-in-30 year event before the middle of the century' (Global Food Security Programme 2015). 
The onset of the global price turbulence had profound effects on the lives of individuals and families on low and precarious incomes. First there was the surge in prices and then there was uncertainty. In most cases wages did not adjust, at least not immediately, and instead it was people who did the adjusting in a multitude of ways. Economic and welfare decisions of different governments before and after food price hikes varied with political, ideological, legal and bureaucratic conditions, as did the way local cultures and individual situations influenced decisions.

The first food price hikes happened at the same time as rapid rises in the global price of energy. At the time the general cost of living was increasing and the number of necessities that people on low incomes were paying cash for - education, health care, water, toilets, rent, transport, food - rose. People told us of an insatiable need for cash. Whereas in the recent past it was normal for many people to grow food, have a place to live, collect water and fuel, or earn most or all of them in kind, today cash is needed for almost everything by an increasing number. Food and other basics have become commoditised, and their value has become monetised. Binding people into a new cash-earning way of life, this commodification has also allowed other values to emerge afresh, such as novelty, taste, convenience and status, a social and economic process elaborated by Appadurai in his seminal introduction to the book The Social Life of Things (Appadurai 1986: 3-63). Monetary commoditisation has underwritten a seismic shift in people's work lives and in livelihood patterns across the world, translating for a vast number into working long hours in difficult, dangerous and precarious jobs.

We do not intend to argue here that food prices, fuel prices, cash requirements or new work patterns are specifically causes or effects, or to try to account for the degree to which one or the other had the upper hand when it came to impacts and change. Our intention is to show patterns of change and to demonstrate the mechanisms of often irreversible decisions that lay the foundations for and consolidated that change. In every one of the 23 sites in ten countries to which we made annual visits between 2012 and 2014, our researchers met people whose lives had changed sometimes dramatically who had moved from the rural to the urban areas, had taken on two or more informal jobs, had made new sacrifices or were taking new risks; all in order to find the resources to care for, feed, clothe and educate the family. The results, country by country, show a pattern of often profound change in how people earn a living, how they eat, where they live, how their families and other relationships work and how they manage domestic care.

These changes seem to have moved faster than policy. While many governments have acted to legislate or implement programmes to secure food supply, stabilise prices or provide targeted welfare, many have been less quick to notice that large swathes of the population are now living quite differently - crammed into urban areas, undertaking more precarious jobs (underpaid, uninsured, insecure), eating less nutritious, less healthy but more calorie-rich and tasty foods, and with less time and resources for unpaid care than ever before. The social costs of managing change when food prices rise or are volatile are often invisible to policymakers. There has been much made of effects on expenditure, because these effects can be assuaged by economic growth, but less on non-monetary effects like having to eat risky foods or change the way the family copes with care (Hossain et al. forthcoming). National statistics are generally showing positive changes to calories or to income per capita, but have less to say about new micro-nutrient deficiencies or new economic stresses when wages do not line up with necessary expenditures. Families interact in new ways now, children are brought up differently and gender relations have changed. In many cases people are telling us about changes for the better - they are modernising, feeling more independent, eating new and tasty foods, having new experiences. But in every location and almost every household in our study there have been decisive stresses that are reducing the quality of life. From what people tell us, their new situation is intricately related to a rising but otherwise uncertain cost of living.

\section{The research}

People's responses to local food price volatilities have been part of a process of rapid social change, the mechanisms of which are complex and not always understood in their full social and political context. The Life in a Time of Food Price Volatility project set out to understand not just the changes themselves, but also the mechanisms by which they are coming about. It is a four-year research project (2012-15) monitoring the impacts of, and responses to, volatile food prices in poor communities in ten developing countries. It aims to inform short-term efforts to help people cope with high and fluctuating food prices and to influence the design of food security and social protection responses over the longer term. We aim to generate evidence about how high and unpredictable food prices affect overall wellbeing and development in poor or vulnerable communities. 


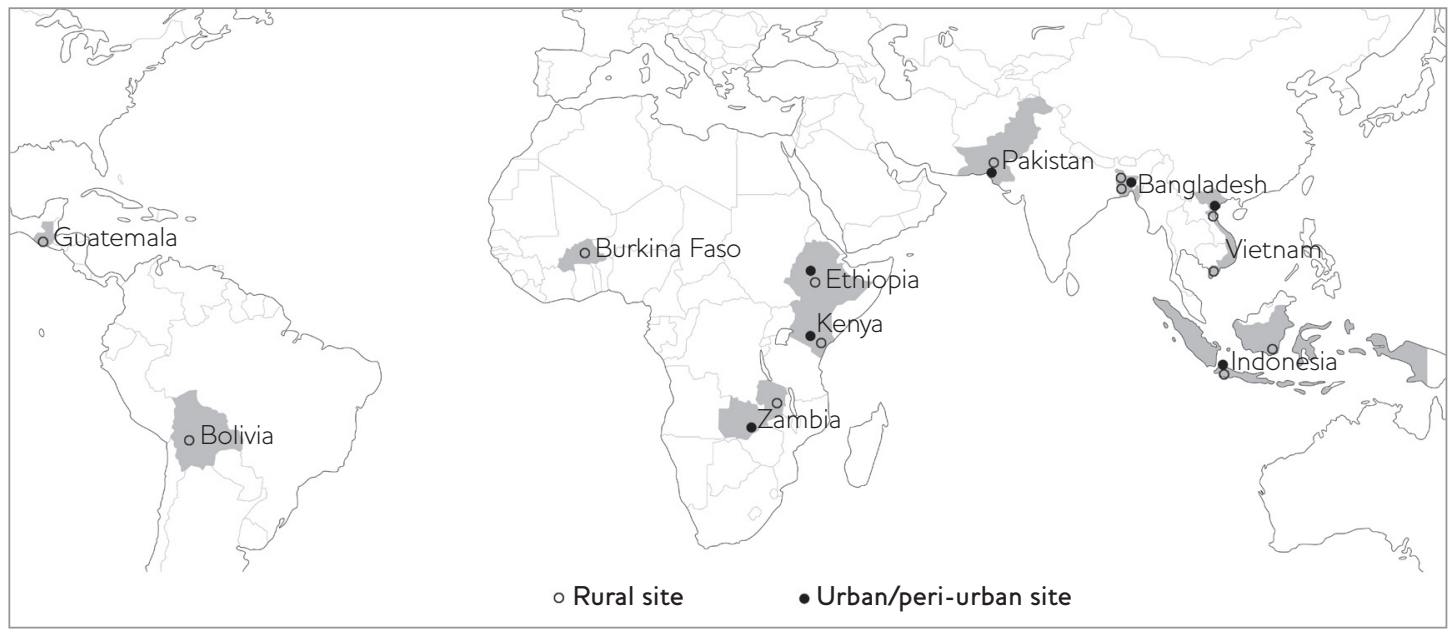

Source Richard King, Oxfam.

Specifically, we looked at the following aspects of high and unpredictable food prices:

1 How they affect the essential day-to-day work of keeping families fed and cared for;

2 How well the support systems on which people routinely rely - whether state or non-state - help people cope with sharp changes in the cost of living.

With funding from UK Aid and Irish Aid, Life in a Time of Food Price Volatility is a collaborative project between Oxfam GB, IDS and our research partners in the ten focus countries (Bangladesh, Bolivia, Burkina Faso, Ethiopia, Guatemala, Indonesia, Kenya, Pakistan, Vietnam and Zambia: see Figure 1). In each country, up to three sites were selected, with at least one urban and one rural site and sometimes a third peri-urban site (Bangladesh, Indonesia and Vietnam). Thus, the research was carried out in 23 sites - ten urban/peri-urban and 13 rural locations - across ten low- to middle-income countries. Although case studies could by no means be seen as representative of these countries, the research sites were generally selected to be broadly typical of conditions in the region or province. Some were locations in which the researchers had worked before, where they had built rapport with the community and knowledge of the setting. Other research sites were specifically selected because of how the community was exposed to global economic volatilities, as the research originated during the 'Triple F' (food, fuel and financial) crises of 2008.
The sites were chosen to provide insight into mechanisms of response to food prices. For example, Dadu District in rural Pakistan had been affected by the 2010 floods, so we knew that a combination of recovery and price rises was going to offer important insights into household decisions. In Bangladesh, of the two rural sites, Naogaon was chosen for its concentration of people living in extreme poverty, while the other rural site, Khulna, was selected because it was badly affected by the cyclone Aila in 2009. We chose the urban site in Bangladesh to give insight into decisions that were being made in a community in which garment workers, many of them women, were responding to economic turbulence. In the same way, sites in Indonesia, Bolivia, Zambia and the other countries were chosen for their ability to tell us something about change for people under stress of low incomes, precarious jobs, or insecure production. We established basic criteria of relative poverty, stress and opportunity in 2009, when we began an earlier research project in Bangladesh, Indonesia, Kenya and Zambia entitled the Social Impacts of Crisis. ${ }^{3}$

In each site, the research generated evidence through household interviews and interviews with local leaders, teachers and other people with understanding of or particular roles in the community, as well as focus group interviews with male and female youth, adults and elderly people. The iterative nature of the interviews, repeated each year between 2012 and 2014 (and in some cases every year from 2009 to 2014) means that our findings go much beyond the strict confines of wellbeing and coping mechanisms. 


\section{How do macro-events have macro-effects?}

The research design arises from our desire to understand the real effects of these price spikes on people's lives and in turn to provide explanations about how these effects have led to major social change. A macro-event, like a global spike in the price of food, does not just lead to a macro-effect, like major shifts in social relations, without going via local micro-effects and responses. The route from macro-condition to macro-outcomes is made up of a myriad of individual and group decisions and circumstances. Between the event and the outcome are mechanisms of change. The project used a methodology specifically designed to trace the route from macro-situations through micro-situations and response to aggregated macro-social change. In each of the articles in this IDS Bulletin we see a part of that journey, mapping some of the mechanisms and understanding where the costs and stresses lie in various cases. Detailing these mechanisms means that people who want to respond to food price volatility (whether in global fora, national policy, social leadership or at the level of household decisions) will be able to select fitting courses of action, because they will have a clearer view of how the changes they are observing came about.

Naomi Hossain's article comes first in this IDS Bulletin, detailing the project methodology and the theory on which it is based. She challenges us not to accept either the imprecision of grand generalisations, the fascination of local particulars or the seductions of statistics and causal modelling to fill in the detail between macro-event and macroeffect. Instead she shows us how we can use detailed local descriptions from people's own perspectives to generate new social theory. The methodology was built from the theory of social mechanisms, an analytical approach to sociology (Hedström and Swedburg 1998; Hedström and Bearman 2009; Hedström and Ylikoski 2010; Wan 2012). It suggests that since it is actors that take action in response to situations and events, then it is not so much variables that social researchers should track, but processes of action. The analysis provides 'a meaningful connection between events' (Coleman 1986: 1327-8).

This IDS Bulletin is structured according to the basic elements of this theory, with sections within the issue that allow us to see ( 1 ) processes of macro-micro impact of food price hikes; (2) processes that take us from micro-impact of rising or uncertain prices to micro-actions by families and individuals; and (3) the process by which multiple micro-actions led in different locations to macro-social change. In the first section, the articles show how global and national prices changed and indicate the broad immediate impacts on people on low incomes. In the second section, the articles show how the severity of the price shocks led to sometimes incremental but sometimes quite dramatic and irreversible decisions about how to manage. The articles in the third section give insight into more generalised patterns, showing how people's reactions, both independent and playing off each other, aggregated to create new social arrangements, new consciousnesses and shifting norms.

\section{Macro to micro}

We begin the 'macro-micro' section with an article by Richard King, detailing volatility in food prices at a global level and asking if it will happen again. This is followed by two articles that present national-level macro-data on food prices and food security, in Kenya (Nick Chisholm), and Bolivia and Guatemala (Gabriela Alcaraz V.), respectively. They demonstrate the utility of having consistent and disaggregated data on food, but also indicate how important it is to effective policy to be able to complement quantitative with qualitative data, to learn more about the mechanisms by which people and society are affected.

Most people on precarious incomes feel the impact of sudden changes in food prices acutely. The availability and affordability of food in the market may change, as we found in Bolivia, where the traditional food quinoa is no longer affordable or always available, or in Burkina Faso and Kenya where packet flavourings and fast foods are increasingly offered as a substitute for meat, or in Indonesia where we found that noodles are increasingly available as a quick alternative to rice. For those on the lowest incomes, the impact may come second-hand. For example, in Pakistan, food price hikes led to changes in patronage and charity and reduced support for people who have depended on these sources of income or insurance to help them get over idiosyncratic shocks.

\section{Micro to micro}

Individuals and households assimilate the impact of macro-events and take action. Their decisions are complex, based on historically-, socially- and psychologically-informed beliefs, desires and fears, as well as on social structures like norms, authorities, peer pressures and information. When food prices hit the roof, our research teams found mechanisms that included reducing the amount of food on the table, buying cheaper, faster, more risky or just different food, taking on additional work or moving 
to a new place and splitting up the family. In the micro-micro section, we detail just a few of the most arresting impacts and responses. Mulumbi shows us how the food on the Zambian table changed after the price hikes and notes how, though prices have since stabilised and even reduced, many households have not returned to their previous diet. Jahan, Rashid and Wahab report changes to life in Bangladesh and speculate on reasons as to why people react to food price hikes by coping and praying rather than getting angry with their government. They eat disgusting foods or get by on ephemeral energy from fried snacks, work harder, migrate to new places and press those who might give them aid, but they do not often complain about evident failures of governance in leading them into these difficult circumstances. In Pakistan, Gazdar explores government reactions to food price volatility in the light of political pressures and concludes that the government has a basic interest in stabilising prices, but not in reducing hunger. He then turns to the reactions of people on very low and precarious incomes to food price increases and points out that the poorest are in some ways insulated from the effects of price because much of their food comes to them through patronage or through different forms of subsistence production or gathering. When these sources dry up, they eat less. The food economy of the poor may protect them from starvation but not from periods of severe hunger. In Ethiopia, Woldehanna and Tafere show how people move away from traditional foods in response to food price rises, but note that, unlike in Bangladesh, the government feels the pressure of their expectations of fair treatment, creating reactions within the policy sphere. In Vietnam, we learn from Tran Cong Thang that strong government price control does not mean that global food price volatility has no effect. Instead, he shows that producers feel increasingly under pressure to overuse chemicals on their crops to supply valuable export markets, endangering the health of consumers.

\section{Micro to macro}

In the third section we look at micro to macro transformational mechanisms. These are the collective effects that become apparent in the aggregate. The decisions that each householder makes in response to crisis are not made in a vacuum. They are usually aware of what others are doing in response to the same shock, and they react accordingly. They may imitate one another - for example, one person may move to the city and then more will follow - or they may respond to opportunities opened up by other people's reactions
- for example, they may sell their peri-urban farmland to new migrants and thus have to take up a new way of making a living themselves.

Perhaps the transformation that has been least visible to policymakers or social commentators has been the change in patterns of care. Food and care are tightly bound, as indeed are work and care. In almost every location women, who are generally the cooks and carers, are taking on more paid work, often outside the home. This means they have less time for care for the very young, the old and the sick. Care is being squeezed into the spaces between paid work (Hossain, King and Kelbert 2013), or in some cases part of it is taken up by the state, in ways that are transforming societies. In the third section, we gather the articles that show most clearly the profound transformations that are under way. In Indonesia, for example, Nurbani shows us how the combination of food price volatility, urbanisation and the rising number of working women and the subsequent decrease in time available for care work has led to great increases in children's snacking and the consumption of pre-prepared and instant foods. This, the author claims, has contributed to a phenomenon of 'hidden hunger', where national data pertaining to the quantity of food consumed masks the reality of deficiencies and poor nutrition along with problems of discipline and family dislocation.

Olivet López, in her article from Guatemala points to the rapidly disappearing culture of eating around the fire, stemming from the rise in firewood prices. This also means that children are no longer taught the essentials of the tradition, history and culture, leading to change in Guatemalan society. From Burkina Faso, Ludovic Kibora shows how food price volatility has led to major shifts in patterns of work (for example, people take jobs far away from home or they travel more and have less time at home). As men eat tasty snacks on the run, they provide less money to those family members at home and the quality of home cooking is called into question. Rosario Léon, in Bolivia, shows us life changes that have come about in part as a result of food price hikes. For example, many farmers have sold their land and taken up waged labour, making them more vulnerable to food price volatility. Others moved to urban areas and began to eat packaged and processed foods, which are cheaper and quicker to prepare. The effects on quality of life have been mixed and for those on low incomes there has largely been an increase in stress. Léon points to the disconnection between the government's 'Vivir Bien' (Living Well) policy and the day-to-day reality 
of many Bolivians, noting that the profound cultural costs of food price volatility are more complex and difficult to resolve than pro-poor government policy in Bolivia has assumed.

\section{Conclusions}

The significance of the price shock comes through in every one of the country case studies. Millions of people have made decisions that though they may not be completely irreversible, are not being reversed. Life has changed. Homes have changed, women have found new roles, children have learned new ways of eating, families have re-oriented their centres of gravity. Our interlocutors in villages and urban areas showed how these shifts often came about quite suddenly. The costs of these changes can be seen in increased stress. The social fabric that people have relied on during previous cost-ofliving crises have started to unravel. Many stories tell of less solidarity between neighbours or even family members. The solidarity is still present, but it is less automatic than it might once have been. We saw more and more people turning towards the, as yet, unreliable, inadequate, badly timed and often corrupt, but less socially burdensome formal sources of welfare, because these come without expectations of reciprocity. In an age of price uncertainty and increasing demands on household income, many people feel that old style reciprocities are no longer suited to their lives.

Other stories tell of women having to fit in care duties after long hours of paid work outside the house, and cooking is getting quicker or even in some cases disappearing altogether. In many locations men are travelling further to work, only to find their jobs ever less secure; they are eating fast-food calories that often lack valuable micro-nutrients and they are increasingly eating apart from their families, changing the ways in which families interact.

\section{Notes}

1 www.fao.org/economic/est/issues/volatility/ en/\#.VehT7beG6ag.

2 www.fao.org/news/story/en/item/296333/icode/.

\section{References}

Appadurai, A. (1986) 'Introduction: Commodities and the Politics of Value', in A. Appadurai (ed.), The Social Life of Things: Commodities in Cultural Perspective, Cambridge: Cambridge University Press Coleman, J.S. (1986) 'Social Theory, Social Research, and a Theory of Action', American Journal of Sociology 91.6: 1309-35
Nutritional and poverty measures suggest that people have coped well, because the measures neglect the detail of how coping and resilience is actually achieved and who is paying the price. There are all kinds of non-monetary effects on family, social or gender relations; there are psychological problems; people find themselves obliged to eat foods they fear. In development discourse, though concerns about micro-nutrients and non-communicable diseases have gained ground in recent years, the general perception is that we are making good progress because we can record increased income and increased calories. These achievements notwithstanding, if development means wellbeing, we are not making as much progress as we think. Calories and income are being bought at a cost of malnutrition, stress and attenuation of care. Of course, these shocks are also unlocking many kinds of beneficial opportunities as people react and look for new ways of making a living, educating their children and fulfilling their social and familial obligations.

The first price spikes were almost a decade ago in 2008. Recent stabilisation of prices may indicate that the situation is under control. But it seems that government social policy may be lagging a decade or so behind the reality for people under stress. Stabilising prices, while welcome, is neither assured, nor is it going to be enough to provide development opportunities to those who have already been forced to change their way of life, for whom high prices remain a crucial barrier to improvements to life and for whom cultural change has swept away much that they once could rely on. It is time to start thinking not only about stabilising the price of food, but also making it possible for citizens to have greater control over what and how they eat, alongside rights to care, equitable gender relations and a fair working environment.

3 More information on the earlier rounds of research is available from www.ids.ac.uk/ idsproject/the-social-impacts-of-crisis.

Global Food Security Programme (2015) Extreme Weather and Resilience of the Global Food System, www.foodsecurity.ac.uk/assets/pdfs/extremeweather-resilience-of-global-food-system.pdf (accessed 16 September 2015)

Hedström, P. and Bearman, P. (eds) (2009) The Oxford Handbook of Analytical Sociology, Oxford: Oxford University Press 
Hedström, P. and Swedberg, R. (1998) Social Mechanisms: An Analytical Approach to Social Theory, Cambridge: Cambridge University Press Hedström, P. and Ylikoski, P. (2010) 'Causal Mechanisms in the Social Sciences', Annual Reviere of Sociology 36: 49-67

Hossain, N.; King, R.; Kelbert, A.; Scott-Villiers, P. and Chisholm, N. (forthcoming) 'Delicious,
Disgusting, Dangerous: Eating in a Time of Food Price Volatility', Brighton and Oxford: IDS and Oxfam

Hossain, N.; King, R. and Kelbert, A. (2013) Squeezed: Life in a Time of Food Price Volatility, Tear 1 Results, Brighton and Oxford: IDS and Oxfam Wan, P.Y. (2012) 'Analytical Sociology: A Bungean Appreciation', Science and Education 21: 1545-65 